\title{
REFORMAS RELIGIOSAS E A EXPANSÃO DO ACESSO À EDUCAÇÃO
}

\author{
Gustavo Kosienczuk Gomes ${ }^{1}$ \\ Soraia Kfouri Salerno ${ }^{2}$
}

Resumo: Este trabalho estuda os movimentos históricos da religião cristã, comumente conhecidos como reforma e contrarreforma (expressão rejeitada por nós), e suas contribuições para a educação, considerando essencialmente a expansão do acesso a esta em sua forma sistematizada. 0 interesse é destacar as propostas e ações de cada lado, protestantes e católicos, e perceber de que maneira estes elementos contribuíram para que mais pessoas tivessem a oportunidade de ter contato com o conhecimento elaborado. A partir da trajetória histórica das concepções e organizações eclesiásticas, destacando experiências significativas do ponto de vista educacional, que, por vezes, eram essencialmente questões políticas. Objetivamos demonstrar as implicações educacionais que estes movimentos trouxeram ao longo da história até a chegada ao Brasil. A pesquisa se respalda numa vertente qualitativa, mediante procedimentos de pesquisa bibliográfica, usando como referenciais estruturantes os autores Hsia (2010), Lindberg (2001), Luzuriaga (1976) e Pereira (2012). Procuramos traçar as relações entre os movimentos religiosos e as ações políticas propostas com objetivos educacionais, seja pelo Estado ou pelas próprias igrejas, apoiados em historiadores que se debruçaram sobre o tema. Percebemos que as mudanças religiosas afetam e são afetadas pelo contexto político, pela visão da pessoa humana e de mundo.

Palavras-chave: Acesso à educação. Cristianismo. Educação. Reformas religiosas.

${ }^{1}$ Graduado em Pedagogia UEL. E-mail: qustavo.kosienczuk@uel.br

${ }^{2}$ Professora do Departamento de Educação da UEL, Doutora em Educação. E-mail: soraiakfouri@uel.br 


\section{RELIGIOUS REFORMS AND THE EXPANSION OF ACCESS TO EDUCATION}

Abstract: This research is focused on the historical movements of the Christian religion, commonly referred to as Reformation and Counter Reformation (expressions rejected in this work), and their contribution to the education, mainly considering the expansion of the access to the education in a systematized way. The main objective is to highlight the proposals and activities of both, Protestants and Catholics, and analyze how it contributed to create opportunities for people to come into contact with the developed knowledge. This is accomplished from a point of view of the historical development of the notions and ecclesiastical organizations, outlining those dealing with education, that occasionally turns into just a political matter. The aim is to demonstrate the educational implications that such movements entailed through the history until their arrival to Brazil, with regard to the access to the formal education. This work is supported by a literature research, using as structural references the authors Hsia (2010), Lindberg (2001), Luzuriaga (1976) and Pereira (2012). We attempt to trace the relations between the religious movements and the political actions proposed with educational objectives, either by the State or the Church, based on historians focused on the topic. It's a seemed fact that religious changes affect and are affected by the political setting and the vision of the human person or of the world.

Keywords: Access to schooling. Christianity. Education. Religious reforms.

\section{LAS REFORMAS RELIGIOSAS Y LA AMPLIACIÓN DEL ACCESO A LA EDUCACIÓN}

Resumen: Este trabajo estudia los movimientos históricos de la religión cristiana, comúnmente conocidos como reforma y contrarformación (expresión rechazada por nosotros), y sus contribuciones a la educación, considerando esencialmente la expansión del acceso a la misma en su forma sistematizada. El interés es resaltar las propuestas y acciones de cada lado, protestantes y católicos, y ver cómo estos elementos contribuyeron para que más personas tuvieran la oportunidad de tener contacto con el conocimiento elaborado. Desde la trayectoria histórica de las concepciones y organizaciones eclesiásticas, se destacan experiencias significativas desde el punto de vista educativo, que a veces eran cuestiones esencialmente políticas. Nuestro objetivo es demostrar las implicaciones educativas que estos movimientos trajeron a lo largo de la historia hasta llegar a Brasil. La investigación se apoya en un enfoque cualitativo, utilizando procedimientos de investigación bibliográfica, utilizando como autores de referencia a los autores Hsia (2010), Lindberg (2001), Luzuriaga (1976) y Pereira (2012). Tratamos de rastrear las relaciones entre los movimientos religiosos y las acciones políticas propuestas con fines educativos, ya sea por el Estado o por las propias iglesias, con el apoyo de los historiadores que trataron el tema. Nos damos cuenta de que los cambios religiosos afectan y se ven afectados por el contexto político, por la visión de la persona humana y del mundo.

Palabras clave: Acceso a la educación. Cristianismo. Educacion. Reformas religiosas 
Introdução

Do século XV ao XVI, o mundo passou por grandes transformações em um período chamado de Renascentismo - Renascença ou Renascentismo - o qual o poder, até então hegemônico, da Igreja Católica começou a regredir de forma intensa. (ARANHA, 1989).

Dessas transformações vale a pena destacar a transformação diretamente religiosa para perceber impactos em todas as áreas da sociedade. Mesmo dentro da religião a valorização humanista das potencialidades humanas provocou fortes mudanças, surgiu uma nova compreensão da fé Cristã.

Junto a essas transformações havia o surgimento de um novo ideal de educação, 0 ideal humanista, que, liberto do dogmatismo e autoritarismo eclesiástico, valoriza as capacidades humanas e seu desenvolvimento, o direito de todos aprenderem da observação direta e de experimentarem. (LUZURIAGA, 1976).

A educação era o principal instrumento da Reforma, Martinho Lutero defendia que todos lessem a Bíblia, mas para isto era preciso saber ler. Na Renascença a expansão da oferta de colégios já atestava a preocupação que se tinha com a educação, não só isso, mas também a produção teórica dos pedagogos. Nesse novo cenário, a educação é moda e exigência para essa concepção de ser humano. (ARANHA, 1989).

Este trabalho consiste em uma revisão bibliográfica, com a metodologia de uma pesquisa qualitativa que, para Silva e Menezes (2005), tem um caráter dinâmico, integrando mundo e sujeito indissociavelmente, interpretando fenômenos e significando-lhes. Buscamos levantar dados sobre o objeto em sua multiplicidade de posições, situando as fontes em suas perspectivas sobre o tema.

Numa abordagem histórica e dialética, recorremos a fontes sobre História, História da Educação e História da Religião Cristã. Como núcleo referencial, foram utilizadas fontes como: Hsia (2010), que nos ofereceu uma perspectiva católica sobre a Reforma; Lindberg (2001) oportunizou uma análise sob a perspectiva protestante a respeito da Reforma; Luzuriaga (1976), historiador da educação, revelou-nos sua percepção dos fatos abordados; e Pereira (2012), trouxe-nos a atuação católica, pela Companhia de Jesus, na cidade de Évora, em Portugal.

Objetivamos com este trabalho elucidar o processo de expansão do acesso à educação, que, pela primeira vez, passa a ser responsabilidade do Estado pela proposta de Martinho Lutero, o Reformador da Alemanha. (ARANHA, 1989). Sendo assim, como 
problema de pesquisa, a questão: quais elementos evidenciam a correlação das reformas religiosas com a expansão do acesso à educação? Compreendendo que analisar o processo histórico envolvendo estes diálogos e disputas de poder são necessários para a elucidação da evolução da educação e progresso da humanidade em um aspecto geral.

0 trabalho foi estruturado em 3 momentos, o primeiro trata especificamente do início dos embates religiosos, dando destaque à pessoa e ações de Lutero, seu contexto, quem foi e quais foram suas propostas. Em um segundo momento, alcançamos o surgimento do movimento religioso protestante, damos destaque a suas proposições educacionais e concluímos com sua presença em terras brasileiras.

Por fim, expomos as ações de reforma da Igreja Católica que se reestruturou diante da nova realidade. Tendo grande parte de sua atuação personificada pela Companhia de Jesus, acompanhamos o trabalho deste grupo em espaço europeu, destacando a presença em Évora, e concluímos apresentando sua relevância em terras brasileiras.

\section{Lutero e a Reforma Protestante}

Reforma Protestante designa um conjunto de acontecimentos do século XVI que deu origem a novos movimentos cristãos. Esta ocorreu em dois momentos, sua origem, centralizada na Alemanha e em Martinho Lutero, e a Reforma Tardia, centrada na Suíça e em João Calvino. (RANDELL, 1995).

Os motivos da Reforma sempre foram muito questionados e raramente compreendidos como apenas religiosos. As compreensões do movimento variam entre: revolução social; questão política; econômica ou; consequência natural do surgimento do pensamento moderno. No século XVI, o mundo passava por grandes transformações

e é impossível apontar para apenas um fator como responsável por tão grande movimento, nos parece que a motivação inicial de Martinho Lutero foi puramente religiosa, mas se beneficiou de seu contexto para obter efetividade e apoio.

Lutero foi um monge agostiniano, mestre em humanidades pela Universidade de Erfurt e Doutor em Bíblia pela Universidade de Wittenberg. Lindberg (2001) nos conta que ele era filho de minerador e o primeiro da família a ingressar na academia. Sua instrução, em Latim, consistia no estudo e no comentário de textos, como Aristóteles e 
escritos sobre lógica. Os debates eram o método da academia, o uso da lógica na busca pela verdade em disputas públicas.

A Reforma surgiu desse meio e se beneficiou da abordagem humanista, que busca o resgate intelectual e crítico, considerando o ser humano capaz de, unicamente pela razão, chegar a níveis mais altos do conhecimento sobre a verdade. (LINDBERG, 2001).

Lutero iniciou seus estudos superiores em 1501, em Erfurt, na Faculdade de Artes. Estudou Gramática, Retórica, Dialética, Geometria, Aritmética, Música, Astronomia, Ética e Metafísica. Em 1505, já era mestre e apto a ingressar no curso de Direito, o fez, mas logo o abandonou e migrou para Teologia, pois havia pedido auxílio à Santa Ana durante uma tempestade assustadora no caminho a Erfurt, onde entra posteriormente em um mosteiro agostiniano. (LINDBERG, 2001).

Sua chegada em Wittenberg foi no ano de 1508, no seguinte se torna Bacharel e em 1512 obtém o título de Doutor em Bíblia. (PROENÇA, 2018). Cursou na Universidade as sete artes liberais (Trivium e Quadrivium) (HILSDORF, 2012), que era o pré-requisito para os cursos de Direito, Medicina e Teologia. Como propor debates era uma obrigação de todo professor, foi este o meio pelo qual Lutero, posteriormente, formulou suas noventa e cinco teses. (LINDBERG, 2001).

Uma reforma era uma necessidade já percebida há séculos por outros, como os Valdenses, os Albigenses, Savonarola, John Wycliff, Jan Hus e Erasmo, que, em sua maioria, assim como Lutero, não queriam romper com a Igreja, mas voltar ao evangelho demonstrado por Jesus em sua vida. (D’AUBIGNÉ, 1951; SIMON, 1971).

A Igreja não era totalmente ignorante de suas deficiências, entretanto não tolerava que a correção viesse de qualquer poder exterior à Roma. Os propositores de reformas se dividiam em três linhas: os reformadores espirituais; os da teoria conciliar; e os humanistas. (SIMON, 1971).

Enquanto os reformadores espirituais condenavam as coisas do mundo e pregavam uma vida piedosa e de austeridade, os reformadores conciliares desejavam um concílio ecumênico para reformar a instituição da Igreja. Os humanistas vinham em diálogo com essas propostas, havendo conciliares entre eles, mas tinham interesses cosmopolitas e priorizavam o intelecto em detrimento da inspiração divina. Estes viam na instrução um meio de melhorar as pessoas, essencialmente boas. (SIMON, 1971).

O Humanismo se originou na Itália Renascentista, um representante importante foi Lefèvre de Etaples, um dos primeiros teólogos a criarem uma tradução vernácula 
(francesa) do Novo Testamento, ele já pregava que todos pudessem ler a Bíblia e expunha com 5 anos de antecedência algumas ideias de Lutero. (LINDBERG, 2001; SIMON, 1971).

As 95 Teses surgiram em 1517, mas não foi sua primeira crítica feita à venda de indulgências, que estava ocorrendo de forma intensa nesse período, em 1514 e em 1516 se manifestara criticando abusos e até mesmo a coleção de Relíquias de seu príncipe. As Noventa e Cinco Teses vieram como uma típica proposta de debate, comum nas universidades e escritas em Latim. (LINDBERG, 2001).

É fácil deduzir que apenas o texto pregado na porta de uma Igreja, anunciando um debate, não teria tanta repercussão, já que leitores eram muito escassos naquele período, é possível que as teses, além de serem fixadas na igreja, foram também copiadas e enviadas para vários outros lugares. (LINDBERG, 2001).

Após isso se decorreram vários conflitos entre Lutero e representantes católicos até um dos momentos de maior relevância desse processo, o Concílio de Trento, iniciado em 1545, na cidade de Trento. (HSIA, 2010). Este concílio reformou dogmas e liturgias, contrapondo-se às novas religiões cristãs, a Igreja reafirmou sua hierarquia, a soberania do papa, seus sacramentos, sua teologia e decidiu que seus padres necessitavam de melhor instrução e preparo. (COSTA; MARTINS, 2010).

O Concílio estendeu-se por 18 anos, até 1563, sendo um marco na história da Igreja Católica. Após o Concílio, a Companhia de Jesus, ordem incumbida da educação, adquiriu importância e permitiu ao papado neutralizar investiduras protestantes e reconquistar territórios. Dele originou-se um Catecismo com as principais doutrinas em forma de manual. Obra que se tornou referência para o ensino da liderança eclesiástica e formação da fé tridentina no Ocidente. (COSTA; MARTINS, 2010).

Após essa contextualização, direcionaremo-nos às atuações pedagógicas e movimentos educacionais dentro do conflito religioso. Para essa empreitada, tomaremos como referência de base a obra História da Educação e da Pedagogia, de Lorenzo Luzuriaga (1976). 


\section{Educação Reformada Protestante}

Para Luzuriaga (1976), a educação da Reforma se fundava na compreensão da necessidade geral do acesso à Palavra de Deus escrita, por isso todos necessitavam dispor da capacidade de leitura.

Lutero foi o propositor da educação como responsabilidade do Estado, considerava básica e essencial a capacidade de leitura para todos os cidadãos e de relevância o conhecimento da matemática e das línguas clássicas para a elite que acessaria a formação de nível médio, mas é Melanchton (1497-1560), o verdadeiro pedagogo da reforma luterana, identificado como “o preceptor da Alemanha”, também foi alçado pelo Humanismo e dedicou sua vida à educação. É o responsável pelo surgimento do ensino secundário na Alemanha e pela inspiração aos demais países, atuou não só na orientação, mas também de forma direta como professor e cátedra. (LUZURIAGA, 1976).

Bugenhagen (1485-1558), outro reformador, além de ser um dos fortes inspiradores da escola secundária pública, junto com Melanchthon, é o principal criador da escola primária. Inspirou na inclusão de diversas ordenações que introduziram preceitos educacionais em várias cdades. Além disso, teve participação na reorganização do ensino universitário e primário da Dinamarca.(LUZURIAGA, 1976).

Outros importantes pensadores alemães no contexto da Reforma foram Trotzendorf, Sturm e Zwinglo, autor do primeiro livro de educação de perspectiva protestante. A educação proposta pela Reforma também era de caráter religioso, Lutero pediu escolas para melhoria da formação religiosa. Em sua "Carta aos regedores de todas as cidades da nação alemã para que estabeleçam e mantenham escolas cristãs", de 1524, solicita:

Portanto suplico a todos, estimados governantes e amigos, pela graça de Deus e pela juventude pobre e abandonada, não considerar isto como assunto sem importância [isto é, a criação de escolas], como fazem alguns que, em sua cegueira, menosprezam os ardis do Inimigo. Pois é um grande e solene dever que nos está imposto, um dever de imensa importância para Cristo e o mundo, prestar auxílio e conselho à juventude. [...]. A prosperidade e bem-estar de uma cidade não consistem somente em acumular riquezas, em construir sólidas muralhas e belos edifícios ou em fabricar armas e munições. Seu melhor e maior bem, sua fortaleza, é contar com muitos cidadãos cultos, polidos, inteligentes, honrados e bem-educados, que possam depois reunir, conservar e empregar bem tesouros e riquezas. (LUZURIAGA, 1976, p. 110). 
Barbosa (2011), estudiosa da temática, refere-se a tal obra com o destaque para a preocupação de Lutero com o ensino ofertado a todos: "Aos conselhos de todas as cidades da Alemanha para que criem e mantenham escolas [...] À nobreza cristã da nação alemã, acerca da melhoria do estamento cristão [...] Uma prédica para que se mandem os filhos à escola”. (BARBOSA, 2011, p. 869).

Apesar de Lutero ter uma preocupação maior com as classes burguesas, ele desperta o interesse das autoridades e assim promove a educação pública para todos. Junto com Melanchthon e Bugenhagen criaram o Ensino Médio humanista de orientação teológica reformada e, com protagonismo deste último, inspiraram uma série de ordenações educacionais municipais em toda a Alemanha. Mais importantes que estas ordenações municipais foram as determinações dos estados, nas quais os príncipes assumiam e determinavam a criação e manutenção de escolas. (LUZURIAGA, 1976).

Ao fim do século XVI, a educação pública alemã já apresentava: escolas primárias, nas quais se lecionava as matérias tradicionais ${ }^{3}$ com leitura das Sagradas Escrituras no vernáculo e cantos religiosos, para o povo; escolas secundárias ou latinas, para a burguesia; e escolas superiores e universidades ${ }^{4}$.

Alguns anos depois do início da Reforma, destacou-se outro grande pensador e líder, Calvino. Não vamos expor todo o contexto histórico e de surgimento do Calvinismo, tomaria-nos muito tempo e páginas. É-nos importante saber que este se iniciou na Suiça e logo se espalhou pela Europa e América. Calvino redigiu em 1538 um programa de governo para Genebra, no qual afirmava que a educação era necessidade pública para boa administração política, defesa da Igreja e manutenção da humanidade das pessoas, por isso as escolas eram necessárias.

$\mathrm{Na}$ Escócia, o movimento calvinista conta com o reformador escocês John Knox, este a tornou no estado mais culto da língua inglesa, impulsionando enormemente a educação. Na Inglaterra, destaca-se o movimento de reforma anglicana, no qual a nobreza seculariza as escolas, enfatiza nestas uma perspectiva humanista e cria a Lei

\footnotetext{
${ }^{3}$ Leitura, escrita e cálculo.

${ }^{4}$ Apesar das proposições de Lutero que não expressavam muita preocupação com a formação popular, só reivindicando o básico, leitura e escrita, são Melanchthon e Bugenhagen os propositores de fato das reformas educacionais, sendo o primeiro o verdadeiro criador da educação humanista pública na Alemanha e na Europa, e Bugenhagen, como já dito, o mais destacado impulsionador e propositor da escola primária na Alemanha. (LUZURIAGA, 1976).
} 
dos Pobres, determinando que as instituições de abrigo não fossem apenas de caridade, mas educativas. (LUZURIAGA, 1976).

\section{Protestantismo no Brasil}

0 movimento calvinista cruzou o oceano, o primeiro momento de contato do protestantismo com o Brasil se deu na experiência da colônia francesa na Bahia de Guanabara (1555-1567). Foi um movimento iniciado pelo partido huguenote ${ }^{5}$ que pretendia estabelecer uma colônia regida pela fé calvinista no novo mundo, mas fracassou quando, em 1567, foram totalmente aniquilados pela perseguição portuguesa e pela inquisição. (DEIROS, 1997).

A segunda tentativa ocorreu em Pernambuco, pelos holandeses, e duraram 31 anos, de 1624 a 1654. Nesta atuação, os holandeses estabeleceram um governo com características calvinistas, prezando pela liberdade religiosa e com sérias regras em respeito aos direitos religiosos de cada um. Apesar de ser um estado protestante, judeus e católicos tinham direito a manterem sua fé e não serem constrangidos por isso. O Governo Supremo do governo civil holandês nesta colônia desempenhava grandes responsabilidades, como a criação de escolas. (DEIROS, 1997).

0 protestantismo entrou livre e abertamente no Brasil apenas no século XIX, após 1810. A família real portuguesa transladou-se para as terras de sua colônia brasileira em 1808, fugindo das invasões napoleônicas e, por terem contado com a ajuda dos ingleses neste deslocamento, concederam livre comércio a eles no ano de 1810. (MARTINS, 2008). Os ingleses trouxeram consigo suas igrejas, anglicanas, inicialmente voltadas apenas para seu povo, com cultos sendo ministrados em inglês. (DREHER, 2013). Temos então que o primeiro modelo de protestantismo a surgir abertamente no Brasil é o protestantismo de imigração, no qual migrantes trazem consigo sua religião para exercerem sua fé como uma questão de identidade cultural. (MENDONÇA; VELASQUES FILHO, 1990).

Com maior presença de imigrantes surgiram discussões sobre os direitos destes. Era preciso discutir a relação da Igreja e do Estado, pois somente pela Igreja Católica, a religião oficial, é que se tinha acesso à participação da vida pública e direitos básicos, como registro de nascimento e casamento. (DREHER, 2013).

${ }^{5}$ Como eram chamados os protestantes franceses, de maioria esmagadoramente calvinista. 
Dos muitos movimentos missionários protestantes que chegaram ao Brasil, o que nos interessa são suas ações educacionais. 0 padrão dos imigrantes protestantes era construir escolas e igrejas para o seu povo, de acordo com nação de origem, destes movimentos, destacamos aqui o dos presbiterianos no relato da ação de Simonton, fundador da Igreja Presbiteriana no Brasil. (ATAÍDES, 2008).

Chegado em terras Brasileiras no ano de 1859, era um pastor presbiteriano vindo para ser missionário. No Brasil, os protestantes já gozavam de liberdade para culto, eram tolerados. Com a Constituição de 1824, eles podiam realizar cultos domésticos em suas comunidades. Simonton morreu jovem, passou apenas 8 anos no Brasil, vindo a falecer em 1867. (ATAÍDES, 2008).

Desde sua chegada, ele militou pela educação, compartilhando suas ideias sobre um plano de se ter no Brasil uma escola protestante de grau elevado para ingleses e brasileiros. Foi o pioneiro no meio protestante brasileiro a reconhecer as escolas como um forte instrumento para a pregação do evangelho, sendo um espaço que não se limita apenas a ensinamentos cristãos, mas no testemunho dos professores e profissionais envolvidos neste trabalho. (ATAÍDES, 2008).

No final do século XIX, a Igreja Presbiteriana já publicara em seu diretório que aos filhos dos membros da Igreja se deve ensinar a ler. Com essa perspectiva positiva em relação às escolas, os missionários se dedicavam irrestritamente na fundação e manutenção destas, bem como para arrecadar fundos e buscar professores. (ATAÍDES, 2008).

Houve também grupos contrários a esta prática, alegando que o investimento de recursos em colégios desacelerava a evangelização. Líderes de várias denominações concordavam com este pensamento e se manifestaram por diversas vezes, mas sempre foram combatidos de forma assídua e firme por outros líderes que defendiam a continuidade das escolas religiosas. (ATAÍDES, 2008).

A escola no meio protestante era compreendida como uma maneira de não só evangelizar, mas também de incluir socialmente muitas pessoas e influenciar a cultura, promovendo novas perspectivas de realidade. Para os fiéis, a escola era uma oportunidade de orientação dentro da doutrina cristã. Outro missionário, Reverendo Horace Lane, era inflexível quanto à presença das escolas na atuação da Igreja junto à comunidade. Afirmava que a campanha evangélica deveria partir do princípio da 
necessidade de escolas, pois na educação da mocidade é que se reúne grande parte de seu ideal. (ATAÍDES, 2008).

Nos movimentos educativos organizados por igrejas ou instituições religiosas a compreensão de base é a necessidade e responsabilidade de desempenhar o papel de influenciar positivamente a nação, difundindo valores morais e modo de vida simultâneo ao desenvolvimento intelectual, emocional e espiritual. (ATAÍDES, 2008).

\section{Educação na Reforma Católica}

Os movimentos protestantes provocando reformas estruturais na sociedade abalaram consideravelmente as estruturas do catolicismo no mundo ocidental, um reflexo muito grande disso foi o impacto que teve nas ordens religiosas. Hsia (2010) comenta sobre isso destacando de início a já citada Companhia de Jesus.

Este autor, ao abordar sobre as ordens religiosas, aponta que Alfonso Salmerón, um dos maiores defensores da autoridade papal no Concílio de Trento, buscou auxílio com seu patriota ao entrar na Universidade de Paris, este auxiliador se chamava Inácio de Loyola. (HSIA, 2010).

Loyola era um nobre vasco que renunciou à carreira militar após um ferimento em batalha e leituras religiosas. Em 1523, decidiu se dedicar aos estudos para se converter em um sacerdote católico e em 1528 vai estudar em Paris. (HSIA, 2010). No ano de 1534, junto com cinco colegas, cria a Companhia de Jesus. Loyola foi estudante do mesmo colégio universitário de Calvino, a Universidade de Paris, seus colegas fundadores também eram todos acadêmicos, o que constitui a origem da Companhia de Jesus como um movimento oriundo das universidades, assim como o movimento protestante. Essa origem nos aponta um compromisso em nível de ensino e pedagogia, compromisso que possibilitou outras áreas de ensino além da teológica. (PEREIRA, 2012).

Em 1540, a Companhia recebe uma aprovação pontifícia, ou seja, torna-se uma ordem monástica oficialmente. Em 1547, é fundada em Sicília a primeira universidade jesuítica, com o envio de cinco jesuítas da parte de Loyola. Deste ano até a morte de Inácio, entre 1547 e 1556, ele fundou mais escolas e deixou funcionando 39 - outros autores dizem 35, como Miranda (2009) - com outras 6 já em preparo.

A atuação educacional jesuítica se baseava inicialmente nos testemunhos de fé de Inácio de Loyola, em suas experiências e formação relatadas nos seus escritos: 
Exercícios Espirituais; e Constituições. Estas Constituições foram as bases do ensino por muitos anos, mas faltavam nelas algo de objetividade pedagógica, intencionalidade acadêmica, pois era muito voltada para uma formação geral do ser humano em comportamentos morais, o que foi revisto na criação do Ratio Studiorum, de 1599, texto fruto de décadas de trabalho jesuítico em instituições de ensino ao redor do mundo, não apenas na Europa. (MIRANDA, 2009).

Como esperado, as escolas jesuíticas inicialmente eram para formação clerical, mas, com o tempo, foi se abrindo às demais pessoas. Veio a ser então a primeira Ordem Religiosa formalmente responsável pelo ensino, fundando diversas instituições. (MIRANDA, 2009; PEREIRA, 2012).

A pedagogia jesuítica era ativa e centrada na disputa. Era uma educação marcada por rigor e qualidade em todas as disciplinas. Sempre foi tratada com uma perspectiva de ser humano integral, o estudante integrado em um modelo de vida com outras pessoas, formando um só corpo. (PEREIRA, 2012).

A visão inicial de Loyola era a de formar pessoas que fossem úteis e relevantes para a sociedade, sendo bons cristãos e cidadãos honestos. Ampliou o público dos colégios para pessoas laicas também tendo esta visão, de beneficiar essas pessoas e enriquecer esta comunidade, com a intenção evangelística de "pescar almas”.

Isto diz respeito à razão de ser da Companhia de Jesus, esta não se encontra nem no combate ao protestantismo, tampouco na finalidade de Educar. Como criada em 1534, tinha o objetivo de evangelizar as pessoas, aperfeiçoar as almas na vida e doutrinas cristãs e propagar a fé. Adquiriu, posteriormente, suas duas principais funções, educação e combate ao protestantismo, pois eram as maneiras mais convenientes naquele contexto para realizar seu objetivo fundante, pois a Igreja precisava enviar pessoas às terras mais distantes. (PEREIRA, 2012).

Importante destacar que a Companhia de Jesus possui uma história dupla em duas dimensões, além do já exposto sobre o pensamento errôneo da função fundante dos Jesuítas ser educação ou combate ao protestantismo, há, por outro lado, uma disputa de discursos que se deram historicamente por conflitos ideológicos e de interesses. Desde as primeiras atuações dos Jesuítas, estes sempre foram vistos com respeito e grande admiração. Não existem muitos relatos sobre suas práticas em dimensões extra catequéticas, mas é amplamente sabido que, por meio de doações, acumularam muitas terras no Brasil. Destas terras, eles, entre desenvolver atividades 
de subsistência, catequéticas e educativas junto à população indígena, conseguiram acumular um enorme capital que, junto à concentração de terras, incomodou a elite política portuguesa, principalmente pelo fato de que os jesuítas protegiam os povos indígenas da escravidão, tirando mão de obra dos colonizadores. (PEREIRA, 2012).

Deste incômodo nasceu um discurso oposto àquele de admiração pelos jesuítas e reconhecimento por suas contribuições para avanço da colonização e bom relacionamento com os povos indígenas. Marquês de Pombal, no século XVIII, iniciou uma contra propaganda agressiva acusando os Jesuítas de serem um peso contrário ao progresso de Portugal, que estes estariam apenas utilizando de privilégios monásticos para enriquecimento próprio e incitando desordem e práticas desviantes no seio dos territórios ultramarinos portugueses. Também se utilizou o argumento, ainda atual em alguns espaços da realidade política brasileira, de que as práticas dos Jesuítas, de criar reservas e assentamentos indígenas reclusos dos grandes movimentos de urbanização e colonização, os excluíam da nova sociedade sendo fundada e impedia que estes fossem integrados ao novo sistema social, sendo prejudicial aos povos indígenas. (PEREIRA, 2012).

\section{Jesuítas em Évora}

Continuando na Europa, passaremos por Évora antes de seguirmos ao Brasil. No dia primeiro de Novembro de 1559 foi oficialmente inaugurada a Universidade de Évora e entregue às mãos da Companhia de Jesus. Em 1759, duzentos anos mais tarde, a universidade encerra suas atividades, sob ordens do Marquês de Pombal, que também expulsa os Jesuítas. Neste intervalo, a Universidade de Évora foi um grande centro cultural a nível nacional, europeu e mundial. (CAPELO, 2010; PEREIRA, 2012). Passado mais 202 anos, em 1961, o P. João Cabral é nomeado superior da Residência de Évora, marcando o definitivo retorno dos Jesuítas à cidade de Évora, fruto de uma saudade e convicção da importância da Universidade. (PEREIRA, 2012; SILVA, 2011).

Os métodos pedagógicos aplicados pela Companhia de Jesus em Portugal ficaram conhecidos como o Ratio Studiorum, foram chamados de monumento pedagógico e eram a referência de Paris. (PEREIRA, 2012).

A Universidade de Évora foi fundada pelo Cardeal Infante Dom Henrique. Antes da Universidade, este já havia formado no Colégio Espírito Santo, sob comando da 
Companhia de Jesus, escolas públicas e era comum a distribuição de bolsas para financiamento do estudo de estudantes mais pobres na Universidade. (PEREIRA, 2012).

Inicialmente as propostas educacionais e ação pedagógica dos Jesuítas subvalorizavam as disciplinas de estudos seculares, como geometria, aritmética e astronomia, mas, com a intervenção do Cardeal, de formação humanista, fez-se concreta a inserção de matérias como lógica, dialética, ética, filosofia, ciências naturais, metafísica e matemáticas, bem como a valorização destas. (PEREIRA, 2012).

Em linhas gerais, a orientação e as estratégias pedagógicas da Universidade foram aplicadas ao modus operandi Jesuíta: Emulações (conclusões e repetições diárias e semanais); Disputas (debates) diárias e públicas; e sessões abertas ao público. Essenciais para a formação de um futuro pregador religioso. (PEREIRA, 2012).

Os registros da instituição do primeiro momento (Pré-Pombalino) mostram claramente a relevância da Universidade de Évora para a formação e desenvolvimento cultural da cidade e do Alentejo, região de Évora. Só nas duas primeiras décadas, o número de estudantes multiplicou-se por 5 . Tudo isto ilustra, contextualmente, a evolução do Humanismo, que chegou tardiamente em Portugal e a efetivação das propostas da Reforma Católica. (PEREIRA, 2012).

Com uma perspectiva deste Humanismo mais desenvolvido e destinado às massas, que rompe com o antropocentrismo, os Jesuítas atuavam pelo mundo. Alguns viveram esta experiência geograficamente, deslocando-se a sociedades distantes, outros experimentaram isso figurativamente, pela curiosidade, investigação e experimentação. A Universidade de Évora era um dos centros desta atividade, recebendo informações dos missionários sobre terras distantes e as estudando, o que estimulava a investigação e a prática científica. (PEREIRA, 2012).

$\mathrm{Na}$ época Portugal desbravava os mares, conquistando várias outras terras, e nestes espaços os jesuítas documentavam, registravam e trabalhavam sobre as novas informações e descobertas. (PEREIRA, 2012). Não nos aprofundaremos muito quanto ao ensino na Universidade, já que este não é nosso foco, mas sim mostrar a relevância que a existência da Companhia de Jesus, que adquiriu um perfil educacional impulsionada pelo movimento de Reforma Católica, teve para a expansão da educação popular.

A seguir, caminhamos com a Companhia de Jesus até o Brasil. Da Universidade de Évora foram enviados alguns missionários jesuítas ao Brasil, 18 apenas em 1570. De todos, não só dos de 1570, destacaram-se muitos, como: Gaspar Álvares, pregador e 
consultor no Colégio da Bahia no fim do século XVI; Paulo de Carvalho, aplicado na aprendizagem da língua Tupi; Manuel Fernandes, dentre vários cargos, Mestre de Noviços e Visitador de Pernambuco na Ocupação Holandesa, e; José Vidigal, missionário de aldeias e reitor do Colégio do Maranhão. (PEREIRA, 2012).

Os Jesuítas foram enviados ao Brasil com a principal função de desempenhar um projeto catequético/colonizador. Este projeto teve início em 1549, quando o Padre Manuel de Nóbrega desembarcou com outros cinco religiosos em Salvador. Essas missões além-mar do grupo jesuítico são originárias de Portugal, partem da iniciativa do Dr. Diogo Gouveia, o Velho, que foi diretor de Paris e principal do Colégio de Santa Bárbara, da mesma cidade. (LEITE, 1965).

\section{Jesuítas no Brasil}

No dia 29 de Março de 1549, a armada de Tomé de Sousa, primeiro governador brasileiro, chega na Baía de Todos-os-Santos, dois dias depois, domingo, é celebrada a primeira missa jesuítica no Brasil, abrindo a história da Companhia na América, inaugurando a missão jesuítica. (LEITE, 1965). Neste período, começou uma enorme produção de documentos sobre suas atividades, como cartas relatando os avanços e recuos da colonização e relatórios sobre a nova terra e seus habitantes. (PEREIRA, 2012).

Logo em Abril do mesmo ano, Nóbrega escreve à Portugal informando que uniu ao ensino catequético, o ensino de leitura e escrita. Confiou esta ao Irmão Vicente Rodrigues e esperou a tradução das orações para o Tupi da parte de Diogo Álvares “Caramuru”. A primeira escola brasileira, fundada por Manuel de Nóbrega, teve como seu primeiro professor Vicente Rodrigues, o Vicente Rijo. (RIBEIRO, 1959).

Com o tempo, os Jesuítas adquiriram grande importância no processo de colonização, como planejado e se tornaram peça fundamental deste, por isso recebiam grandes doações, inclusive de terras, assim construiam espaços escolares, principalmente para catequização. No Rio de Janeiro, registros os apontam, entre outras funções, como administradores de instituições de ensino. (PEREIRA, 2012).

Os jesuítas foram, na pessoa de José Vidigal, eborense, responsáveis por estabelecer o padrão das catequeses em Tupi, o que proporcionou maior contato e interação com os povos indígenas e aprendiam a ler e escrever em seu próprio idioma. 
Apesar do Tupi não haver sido o único idioma falado entre os povos indígenas, este foi um avanço enorme, principalmente considerando as missões de paz sucedidas eficazmente entre as novas comunidades alcançadas. (PEREIRA, 2012).

Outra grande ação em prol do Tupi foi a produção da Arte Grammatica da Lingua Brasílica, em 1687, pelo Pe. Luís Figueira, jesuíta alentejano com longa caminhada em missões no Brasil, chegando a ser administrador eclesiástico do Maranhão. Este escrito foi feito tomando como referência falantes nativos do idioma na procura da qualidade de seu trabalho ${ }^{6}$.

Logo no início os Jesuítas perceberam a necessidade de educar a população indígena na religião e cultura, mas, como os povos indígenas possuíam uma maneira de apreender 0 mundo completamente diferente dos europeus, foram empregadas metodologias de ensino completamente diferentes para eles. (PEREIRA, 2012).

É necessário se pensar a educação desenvolvida aqui dentro de um contexto maior, com objetivos e disputas de diversos lados. Os jesuítas haviam sido enviados por Portugal para assumirem a organização da cristandade no Brasil, por meio de suas escolas eles visavam formar os indivíduos dentro dos padrões escolásticos, sendo assim adequados ao projeto português de colonização. (SHIGUNOV NETO; MACIEL, 2008).

Contudo, eles tinham seu próprio projeto, pensado desde sua fundação, o de “evangelizar as pessoas, aperfeiçoar as almas na vida e doutrinas cristãs e propagar a fé”. No Brasil, esse projeto visava também uma transformação social, implementando mudanças na cultura indígena brasileira. (SHIGUNOV NETO; MACIEL, 2008, p. 29).

Projeto que se relacionava constantemente, por vezes em oposição, ao Projeto Português. A atuação dos jesuítas no Brasil se divide em duas fases: no primeiro século, adaptar e construir seu trabalho de catequese e conversão e; na segunda fase, desenvolver e expandir o sistema educacional.

Dessa maneira, podemos compreender a atuação educacional jesuítica. Eles vieram para cumprir, e cumpriram, o objetivo da coroa portuguesa de conversão dos povos indígenas aos costumes, crenças, pensamentos e tradições portuguesas, mas, em um momento posterior, eles investiram fortemente em educação e na formação humana com maior caráter próprio dos religiosos. Todo esse trabalho foi baseado em educação.

\footnotetext{
${ }^{6}$ Antes deste, outro conhecido Jesuíta já havia contribuído para a compreensão desta língua e na produção linguística acerca dos povos nativos brasileiros. Em 1595, o Pe. José de Anchieta publicou seu livro Arte de Gramática da Língua mais usada na Costa do Brasil (1595).
} 
Já em sua chegada, a Companhia de Jesus erigiu a primeira escola de ler e escrever, na Bahia, em Agosto de 1549. Portugal não possuía um sistema sólido de ensino. Ao chegar, Padre Manuel de Nóbrega expôs um plano de estudos organizado em duas fases. Primeiro o ensino elementar, que compreendia o ensino do português, da doutrina cristã e a alfabetização; e, para a segunda fase, era opcional entre um ensino profissionalizando e o Ensino Médio. (SHIGUNOV NETO; MACIEL, 2008).

0 Padre Manuel de Nóbrega era conhecido como o grande defensor dos povos indígenas, ajudou na fundação de muitas aldeias ao longo de sua vida, mas sua maior contribuição foi na área educacional. "Sob seu comando foram fundadas 5 escolas de instrução elementar, (em Porto Seguro, Ilhéus, Espírito Santo, São Vicente e São Paulo de Piratininga) e três colégios (no Rio de Janeiro, Pernambuco e Bahia)”. (SHIGUNOV NETO; MACIEL, 2008, p. 177). Nóbrega, algumas vezes, até mesmo passava por cima das ordens de seus superiores para empreender seus projetos em auxílio aos povos indígenas. (SHIGUNOV NETO; MACIEL, 2008).

Foi ele quem nomeou o primeiro professor a ministrar aulas no Brasil, no Colégio da Bahia (A primeira escola da Bahia, que fora transformado em Colégio dos Meninos de Jesus), o já citado Vicente Rodrigues, conhecido como Vicente Rijo. 0 irmão do Ministro do Colégio de Belas Artes de Coimbra tornou-se um jesuíta aos 17 anos. Com 21 anos assumiu o cargo direcionado por Nóbrega, no qual atuava com catequese e alfabetização de indígenas. (SHIGUNOV NETO; MACIEL, 2008).

Importante destacar que um forte recurso didático utilizado pelos jesuítas no ensino aos povos indígenas era o teatro, sendo realizado tanto nas aldeias, pelas praças, como nos colégios. Em vários formatos, breve ou longo, com atores portugueses ou indígenas, o teatro sempre esteve presente no processo de interculturação desenvolvido pelos jesuítas, que podem ser considerados os precursores das artes cênicas no Brasil. (FERREIRA JUNIOR; BITTAR, 2004)

Seria impossível esboçar a totalidade da ação e da contribuição jesuítica para a difusão, desde sua introdução, da alfabetização em terras brasileiras. Porém, é importante conhecermos o princípio deste trabalho para identificarmos a contribuição que estes movimentos de reformas religiosas tiveram na expansão do acesso popular às letras que, em sua época, era disponível a um público extremamente reduzido. 


\section{Considerações Finais}

Nos séculos XV e XVI, a Europa vivia sob domínio católico, o mínimo de educação formal que consideramos hoje, a alfabetização, era um luxo concentrado entre os membros do Clero. Discordando das práticas da Igreja e influenciado por pensamentos humanistas, um monge e professor universitário, Lutero, teceu críticas que abalaram as estruturas da sociedade.

Lutero fez exposição de suas críticas como um convite ao debate. Essas críticas rapidamente se espalharam e incomodaram além do esperado. Suas ideias conquistaram as mentes dos príncipes alemães e, somadas aos interesses de libertação do domínio religioso (principalmente da cobrança de tributos), foi suficiente para o início de um movimento de transformação. Centralizando o texto bíblico para uma adequada vida de fé, Lutero militava pelo direito universal de ler a Bíblia e do dever dos governantes, e não da Igreja, de possibilitar o acesso a esse direito, ou seja, criar e manter escolas.

A Reforma se expandiu, Escócia, França, Holanda e Inglaterra adotaram mudanças após aceitaram as ideias protestantes. Os impactos educacionais nestes países foram notáveis e com a descoberta de um novo continente os protestantes lançaram várias tentativas de espalharem sua fé, sem muito sucesso no início.

A Igreja Católica percebeu a necessidade de renovar-se e, carente de uma formação melhor para o clero, incumbiu essa tarefa à Companhia de Jesus. Os Jesuítas fizeram seu trabalho, deram início a diversas instituições e contribuíram para a educação popular. Neste contexto, as escolas tinham papel como símbolo de poder da religião dentro da disputa ideológica, por isso nenhuma das partes se eximia de uma atuação intensa na área. (HILSDORF, 2012).

Com a descoberta do novo mundo (Continente Americano), os religiosos tentaram espalhar suas doutrinas. Portugal e Espanha receberam da Igreja o direito e o dever de conquistar as novas terras e evangelizar seus moradores e os Jesuítas foram incumbidos de trazer a Fé Católica para o novo continente, mas também seguiam seu próprio projeto, tendo a educação para transformação social e conversão em uma posição central.

Este trabalho objetivou elucidar o processo de expansão do acesso à educação, que recebeu forte contribuição das reformas religiosas quando pensamos no acesso 
popular a escolas em um pensamento de que todas as pessoas necessitam de uma escolarização e devem ter esse direito garantido (promovido e mantido) pelo Estado.

\section{Referências}

ARANHA, M. L. A. História da Educação. São Paulo: Moderna, 1989.

ATAIIDES, F. M. Simonton: o missionário que impactou o Brasil. Arapongas: Aleluia, 2008.

BARBOSA, L. M. R. Estado e educação em Martinho Lutero: a origem do direito à educação. Cadernos de Pesquisa, São Paulo, v. 41, n. 144, p.866-885, set./dez. 2011. Disponível em: http://dx.doi.org/10.1590/S0100-15742011000300012. Acesso em: 10 fev. 2019.

CAPELO, L. C. Inventário do fundo documental da Universidade de Évora. Évora: Universidade de Évora, 2010.

COSTA, C. J.; MARTINS, F. J. S. Análise histórica, religiosa e educacional sobre o catecismo do Santo Concílio de Trento. Revista Brasileira de História das Religiões, Maringá, ano 2, n. 6, fev. 2010. Disponível em:

http://www.dhi.uem.br/gtreligiao/pdf5/texto3.pdf. Acesso em: 3 mar. 2019.

D’AUBIGNÉ, J. H. M. História da reforma do XVI século. São Paulo: Casa Editora Presbiteriana, 1951.

DEIROS, P. A. Protestantismo en América Latina. [S. l.]:Editora Caribe, 1997.

DREHER, M. N. História do povo de Jesus: uma leitura latino-americana. São Leopoldo: Sinodal, 2013.

FERREIRA JUNIOR, A.; BITTAR, M. Pluralidade linguística, escola de bê-á-bá e teatro jesuítico no Brasil do século XVI. Educação e Sociedade, Campinas, v. 25, n. 86, apr. 2004.

HILSDORF, M. L. S. O aparecimento da escola moderna: uma história ilustrada. 2. ed. Belo Horizonte: Autêntica, 2012.

HSIA, R. P.-C. El mundo de la renovación católica. Traducción de Sandra Chaparro Martínez. Madrid: Ediciones Akal S. A., 2010.

LEITE, S. L. S. I. Suma histórica da companhia de Jesus no Brasil. Lisboa: Junta de Investigações Ultramar, 1965.

LINDBERG, C. As reformas na Europa. Tradução de Luís Henrique Dreher, Luís Marcos Sander. São Leopoldo: Sinodal, 2001.

LUTERO, M. As 95 teses de Martinho Lutero. 1517. Disponível em:

http://www.luteranos.com.br/lutero/95_teses.html. Acesso em: 4 abr. 2019.

LUTERO, M. Interpretação do novo testamento: Gálatas - Tito. Tradução de Paulo F. Flor, Luís H. Dreher. São Leopoldo: Sinodal; Canoas: ULBRA; Porto Alegre: Concórdia, 2008. (Obras selecionadas, v. 10). 
LUZURIAGA, L. História da educação e da pedagogia. São Paulo: Editora Nacional, 1976.

MARTINS, I. L. D. João VI e a Biblioteca Nacional: um legado em papel. Rio de Janeiro: Fundação Biblioteca Nacional, 2008. Curadoria e textos Ismênia de Lima Martins, Vitor Manuel Marques da Fonseca.

MENDONÇA, A. G.; VELASQUES FILHO, P. V. Introdução ao protestantismo no Brasil. São Paulo: Editora Loyola, 1990.

MIRANDA, M. Código pedagógico dos Jesuítas, Ratio Studiorum da Companhia de Jesus, regime e curriculum de estudos. Setúbal: Esfera do Caos Editores Lda., 2009.

PEREIRA, S. M.; VAZ, F. L. Universidade de Évora (1559-2009), 450 anos de modernidade educativa. Évora: Chiado Editora, 2012.

PROENÇA, W. L. Leituras na reforma e (Re) formas da Leitura. Práxis Evangélica, Londrina, n. 29, 2018.

RANDELL, K. Lutero e a reforma alemã 1517-1555. Tradução de Beatriz Sidou. São Paulo: Editora Ática, 1995

RIBEIRO, F. J. G. 0 primeiro mestre-escola do Brasil. Revista Letras, Curitiba, v. 10, p. 122-125, 1959. Disponível em:

https://revistas.ufpr.br/letras/article/viewFile/19953/13160. Acesso em: 20 jan. 2019.

SHIGUNOV NETO, A.; MACIEL, L. S. B. O ensino jesuítico no período colonial brasileiro: algumas discussões. Educar, Curitiba, n. 31, p. 169-189, 2008.

SILVA, A. Cinquenta anos de jesuítas em Évora, 1961-2011. Revista do Instituto Superior de Teologia de Évora, Évora, ano 24, n. 45, 2011.

SILVA, E. L.; MENEZES, E. M. Metodologia da pesquisa e elaboração de dissertação. 4. ed. rev. atual. Florianópolis: UFSC, 2005.

SIMON, E. A reforma. Rio de Janeiro: José Olympio Editora, 1971. 